\title{
Binding reconstruction and two modes of copy-chain interpretation
}

\author{
Kenyon Branan \& Michael Yoshitaka Erlewine*
}

\begin{abstract}
We present a theory for the interpretation of $\bar{A}$-movement chains at LF in the copy theory of movement where the NP restrictor of a DP $\bar{A}$-movement chain is interpreted in only one copy. Such a view is motivated for English by evidence from reflexive binding, building on observations in Barss 1986, and its interaction with parasitic gap licensing and weak crossover effects. Our approach offers a means for understanding the classification of $\bar{A}$-movement types in Cinque 1990 and Postal 1994 in copy-theoretic terms.
\end{abstract}

Keywords. copy theory of movement; reconstruction; reflexive binding; Binding Condition A; parasitic gaps; weak crossover

1. Introduction. Much work since Chomsky 1993 has developed the idea that movement produces copies. For instance, in the case of the long-distance movement of which cake in (1), copies of the wh-phrase occupy both Spec,CP and the base, object position of the embedded clause, as well as certain intermediate positions. (2) reflects one such possible output representation of movement via copying in the narrow syntax:

(1) Which cake did Amy say that Bob baked?

(2) [which cake] did Amy say [which cake] that Bob baked [which cake]

The resulting copy-chain must then be modified as part of its interpretation at the interfaces. PF requires that only one of these copies be pronounced (Pesetsky, 2000; Nunes, 2004); for this case of overt movement, the highest copy is privileged at PF as in (3a). LF likewise requires that the copies in a chain be modified for interpretation. In particular, the quantificational material of the moved phrase must be interpreted in only one copy, which will be its scope-taking position. Here, we interpret the quantificational determiner which (an existential quantifier if we follow Karttunen 1977) in its highest copy. Lower copies must then be interpreted differently, for instance, as bound definite descriptions (e.g. via Trace Conversion; Fox, 2002) as in (3b).

(3) a. PF: [Which cake] did Amy say [which cake] that Bob baked [which cake]?

b. LF: [which cake] $\lambda x$ did Amy say [the cake $x$ ] $\lambda y$ that Bob baked [the cake $y$ ]

In the case above, the copy privileged for pronunciation at $\mathrm{PF}$ is also the copy privileged for quantificational interpretation (scope-taking) at LF, thus offering a characterization for overt movement without quantificational reconstruction. Pronouncing a copy that is lower than that interpreted at LF allows for so-called covert movement. Choosing a copy that is lower than the pronounced copy for quantificational interpretation results in so-called quantificational reconstruction. (See also discussion in Bobaljik 1995, 2002.) Different modes of chain resolution at the two interfaces thus can account for a wide range of phenomena at the syntax-semantics interface, making the precise description of these processes of copy-chain interpretation of paramount importance for syntactic theory with the copy theory of movement.

\footnotetext{
* We thank Hadas Kotek, Stefan Keine, and Zheng Shen and other members of the NUS Syntax / Semantics Lab for discussion that has informed this work. Authors: Kenyon Branan, National University of Singapore (kgbranan@nus.edu.sg) \& Michael Yoshitaka Erlewine, National University of Singapore (mitcho@ nus.edu.sg).
} 
Note, however, that in the LF representation in (3b) above - the result of Fox's widely adopted Trace Conversion mechanism - the NP restrictor is still present in multiple copies. In this paper, we motivate and pursue an alternative view, where the NP restrictor is interpreted in only one copy of an $\bar{A}$-chain at LF. ${ }^{1,2}$ In other words, just one copy in an $\bar{A}$-copy-chain is privileged for interpretation of its NP, analogous to there being a single privileged copy whose quantificational determiner is interpreted.

This paper is organized as follows. We first lay out a set of observations involving reflexive binding in English $w h$-movement, which motivates this view that restrictor NPs are interpreted in just one copy of a $\bar{A}$-movement chain. We then sketch a bimodal theory of $\bar{A}-$ chain interpretation, which uses different modes of interpretation for portions of the copy-chain above and below the privileged copy where the NP is interpreted. This theory makes a set of predictions about interactions between reconstruction for reflexive binding with parasitic gap licensing and weak crossover effects, which we show to be correct. We furthermore show that the theory of chain interpretation developed here, primarily motivated by properties of English wh-movement, provides a way of understanding differences between two subclasses of $\bar{A}$-movement like that discussed in Postal 1994.

2. Privileging one copy's restrictor. We begin by presenting evidence from reconstruction suggesting that different lower copies of a single chain can — and in some cases must - be distinct. Barss (1986: 25) shows that anaphors can be bound as if their $\bar{A}$-moved containers are interpreted in their base or intermediate positions; in other words these containers may reconstruct for the evaluation of binding conditions. As we see in (4), an anaphor contained in the object of a finite complement clause may be bound by the local subject, but not the subject of a higher clause. However, as (5) shows (based on examples in Barss 1986: 25), when a phrase containing that anaphor undergoes $w h$-movement, it may be bound by either subject. This suggests that either of the two copies (underlined in (4)) may be privileged for the evaluation of Condition A.

(4) Baseline: Amy thinks [(that) Bob likes [some picture of *herself ${ }_{\mathrm{A}} /$ himself $_{\mathrm{B}}$ ]].

(5) a. [Which picture of himself $\left.{ }_{\mathrm{B}}\right]$ does Amy think $t$ (that) Bob treasures $\underline{t}$ ? b. [Which picture of herself ${ }_{\mathrm{A}}$ ] does Amy think $\underline{t}$ (that) Bob treasures $t$ ?

One possibility for describing such facts would be to claim that Condition A is satisfied as

\footnotetext{
${ }^{1}$ Takahashi and Hulsey 2009 argues that copy-chains of A-movement have the NP restrictor in some copies in the chain but not others. However, here we concentrate on $\bar{A}$-movement, and leave a full synthesis of our ideas and theirs for future work.

${ }^{2}$ For most previous work on the copy theory of movement, including the discussion in Fox 2002, the idea that NP restrictors are interpreted multiply seems to be thought of as a harmless null hypothesis, rather than a result that is explicitly argued for. We know of only two families of work that claims to derive positive predictions from this assumption: Based on a suggestion in mid-90's lecture notes by Gennaro Chierchia, Romoli 2015 argues that simultaneous interpretation of NP restrictors in both higher and lower copies serves to explain the conservativity universal of natural language determiners (Barwise and Cooper, 1981), and Erlewine 2014 argues that simultaneous interpretation of NP restrictors in copy-chains helps explain a range of facts regarding focus association and its interaction with movement. However, neither have the force of being strong arguments for the copy theory with multiple interpretation of NPs, as they do not explicitly argue that their empirical facts cannot be explained for without this assumption. In future work, we hope to study interactions (if any) between the binding reconstruction facts discussed here and the phenomena discussed by Romoli and Erlewine.
} 
long as an anaphor is properly bound at some point in the derivation. (See e.g. Belletti and Rizzi 1988, Uriagereka 1988, Lebeaux 1991, Epstein et al. 1998 for proposals along these lines.) Subsequent movement of the container of the anaphor would not cause the anaphor to be delicensed. However, there is reason to think that such a derivational approach to Condition A is not on the right track, and that a single copy of the NP must be privileged instead.

The argument comes from complex noun phrases which contain multiple anaphors. Consider (6), where we see that letter may take at least two types of PPs, both of which behave like the of phrase in (5) for the purposes of reflexive binding.

(6) a. [Which letter from herself ${ }_{\mathrm{A}} /$ himself $_{\mathrm{B}}$ (to Santa)]

b. [Which letter (from Santa) to herself $\mathrm{A}_{\mathrm{A}} /$ himself $\left._{\mathrm{B}}\right]$ does Amy think $t$ (that) Bob treasures $t$ ? does Amy think $t$ (that) Bob treasures $t$ ?

However, when both adjuncts containing reflexives cooccur, bound by distinct antecedents, unacceptability arises; see (7). This shows us that a single position in the $\bar{A}$-chain is privileged for Condition A evaluation, with copies of the NP in other positions rendered inactive. This choice cannot be made separately for the evaluation of Condition A for each reflexive, separately.

(7) a. $\checkmark$ [Which letter from herself ${ }_{\mathrm{A}}$ to herself $\left.\mathrm{H}_{\mathrm{A}}\right]$ does Amy think $t$ Bob treasures $t$ ?

b. $\checkmark$ [Which letter from himself $f_{\mathrm{B}}$ to himself $\left.\mathrm{B}_{\mathrm{B}}\right]$ does Amy think $t$ Bob treasures $t$ ?

c. $*$ [Which letter from herself ${ }_{\mathrm{A}}$ to himself $\mathrm{B}_{\mathrm{B}}$ ] does Amy think $t$ Bob treasures $t$ ?

d. * [Which letter from himself B $_{\mathrm{B}}$ to herself $\left.\mathrm{A}_{\mathrm{A}}\right]$ does Amy think $t$ Bob treasures $t$ ?

The derivational approach to Condition A considered above - where each reflexive must satisfy its binding requirements at one point in the derivation - cannot straightforwardly account for the unacceptability of $(7 \mathrm{c}-\mathrm{d})$. Although there is no single trace position in which both anaphors in the fronted phrase are properly bound, each anaphor is properly bound in at least one trace position; the derivational approach would lead us to expect the examples in question to be grammatical.

A second argument for privileging one copy in a copy chain for the interpretation of its restrictor comes from the interpretation of certain adjectival modifiers in raising relative clauses, discussed in Bhatt 2002. As shown in (8), the adjective only, here modifying the head of the relative clause, book, exhibits a scope ambiguity with respect to the intensional predicate say, itself contained within the relative clause.

(8) the only book that John said $t$ that Tolstoy wrote $t$

(Bhatt, 2002: 58)

a. $\approx$ the book $x$ such that John said that Tolstoy only wrote $x$

b. $\approx$ the book $x$ such that John only said that Tolstoy wrote $x$

Bhatt explains this ambiguity using a raising analysis for relative clauses. The derivation of the relative clause in (8) yields copies of the restrictor including adjectival only both above and below say, with only one of these copies privileged for its interpretation.

We add to Bhatt's discussion the novel observation that reflexives can be used to privilege one particular position over another. As we see in (9a), only may scope either below or above say when the head of the relative clause contains an anaphor bound by the subject of the complement of say. However, when the anaphor is bound by the higher subject, as in (9b), only 
must scope above say.

(9) a. the only picture of himself B that Amy said $t$ that Bob liked $\underline{t}$
b. the only picture of herself A that Amy said $\underline{t}$ that Bob liked $t$

The unambiguous interpretation of (9b) shows that the copy chosen for the interpretation of the adjective only must also be the copy chosen for the evaluation of the reflexive. We note that the high reading is predicted to be independently available, due to an alternate parse suggested by Bhatt whereby only adjoins high, after relativization, explaining the availability of both high and low only readings in (9a).

In sum, evidence from the reconstruction of English $w$ h-moved restrictors for reflexive binding (Condition A) suggests that exactly one copy of a DP $\bar{A}$-chain is privileged for the interpretation of its NP restrictor at $\mathrm{LF}^{3}$

3. Core proposal. We now lay out a proposal which correctly allows exactly one NP position in a chain of DP copies to be interpreted at LF. Consider (10), in which a DP has undergone movement via copying. The quantificational determiner ( $\mathrm{D}$ head) will be interpreted in the higher, derived position; in other words, we do not consider cases of quantificational reconstruction here.

$$
[\langle e t, t\rangle \underline{\mathrm{D}} \mathrm{NP}] \ldots[\langle e t, t\rangle \mathrm{D} \mathrm{NP}]
$$

At least two things must happen by LF for the structure above to receive a proper interpretation. The lower copy must replace its determiner, and it must be bound in some way by the higher copy. Many mechanisms along these lines have been proposed in the literature. One involves binding individual variables: Trace Conversion, developed in Fox 2002, is a prominent example of this. For Fox, the lower D is replaced by the definite determiner the and the higher DP binds an individual (type $e$ ) variable introduced into the restrictor.

$$
\left.[\langle e t, t\rangle \mathrm{D} \mathrm{NP}] \ldots[\langle e t, t\rangle \mathrm{D} \mathrm{NP}] \quad \rightarrow \quad[\langle e t, t\rangle \mathrm{D} \mathrm{NP}] \lambda x_{\boldsymbol{e}} \ldots[\text { [e the [NP } x]\right]
$$

Another option involves binding choice functions (Sauerland, 1998: ch. 5, 2004; Ruys, 2000). On this approach, the lower D is replaced by a choice function; the higher quantifier is converted into a quantifier over choice functions $\mathcal{D}$ and its complement NP is deleted. This is schematized below. There are important questions regarding how exactly the higher quantifier should be made to quantify over a predicate of choice functions, which we set aside here; see Abels and Martí 2010 and citations there for much relevant discussion.

$$
[\langle e t, t\rangle \mathrm{D} \mathrm{NP}] \ldots[\langle e t, t\rangle \mathrm{D} \mathrm{NP}] \quad \rightarrow \quad[\mathcal{D} \mathrm{NP}] \lambda f_{\text {cf }} \ldots\left[\text { e } f_{\text {cf }} \mathrm{NP}\right]
$$

We propose that these two options (or similar) are available for the interpretation of chains. Now suppose that the NP restrictor is interpreted in exactly one position in a chain; all other NPs are deleted. Below this position, binding individual variables is used, following Fox 2002. Above this position, an alternative mechanism is used for chain interpretation, perhaps using

\footnotetext{
${ }^{3}$ We note that much of the earlier motivation for $\bar{A}$-movement involving copying comes from Condition $\mathrm{C}$ reconstruction (see e.g. Lebeaux, 1991; Romero, 1998; Fox, 1999), in some cases explicitly setting aside Condition A data (see discussion in Heycock 1995). But recent work (e.g. Adger et al. 2017; Bruening and Al Khalaf 2019 on English) has questioned the Condition $\mathrm{C}$ evidence (but see also Wierzba et al. to appear on German and Stockwell et al. to appear on English). We do not discuss Condition $\mathrm{C}$ reconstruction facts here and instead endeavor to take the Condition A reconstruction facts, such as that presented in this section, to be primary.
} 
choice functions as in (12), or perhaps through some other mechanism. Here we will describe this non-individual-binding mode of chain interpretation as involving choice function binding.

Consider now a DP movement chain involving multiple copies, again with no quantificational reconstruction. For instance, in (13), there are three positions that the NP might be interpreted in. If the highest position or the lowest position is chosen, the interpretation of the chain will be uniform: all using binding of individual (type $e$ ) variables or all using choice function binding. However, if an intermediate copy is privileged for restrictor interpretation, there will be a split in the chain: below the NP, one mechanism will be used, while above the $\mathrm{NP}$, another will be used. In cases such as this, we might expect to find cases where the two parts of the chain behave differently.

(13) One chain, three copies, two "links":

[1) D NP ] ... [(2) D NP ] ... [3 D NP ] $\rightarrow$

a. [(1) D NP ] $\lambda x_{e} \ldots$ [(2) the $x$ ] $\lambda y_{e} \ldots$ [3) the $y$ ]

(all below the NP)

b. [(1) D ] $\lambda f_{\mathrm{cf}} \ldots$ [(2) $f$ NP ] $\lambda y_{e} \ldots$ [3 the $y$ ]

c. [1) D ] $\lambda f_{\mathrm{cf}} \ldots\left[\right.$ [2 $f$ ] $\lambda g_{\mathrm{cf}} \ldots$ [3 $g$ NP ]

(some above, some below)

(all above the NP)

As we will see, this expectation is borne out. In particular, if we force a medial copy to be privileged for interpretation as a result of Condition A reconstruction, we will see that the two portions of the chain do indeed behave differently.

4. $\overline{\mathbf{A}}$-movement above and below the NP. This section shows that there is evidence for the predicted split in $\overline{\mathrm{A}}$-chains that the theory above leads us to expect. This evidence comes from two sources the effects of Condition A reconstruction on parasitic gap licensing and patterns of weak crossover amelioration.

4.1. Parasitic gap LiCEnsing. Ā-movement licenses parasitic gaps (pg), as shown in (14). Here we see that a gap within an adjunct is licensed just when there is an additional wellformed object gap in the same clause.

[Which articles] did John file __ [adjunct without reading $\underline{p g}$ ]?

(Engdahl, 1983: 5)

We follow Nissenbaum (2000a,b) in our analysis of parasitic gap licensing. Nissenbaum suggests that pg-containing adjuncts involve null operator movement, creating a derived predicate of type $\langle e, t\rangle$. These adjuncts must adjoin to another derived predicate of type $\langle e, t\rangle$, here underlined, formed via intermediate movement of the object through the edge of $v \mathrm{P}^{4}$

(15) [Which articles] $\lambda x \operatorname{did}\left[{ }_{\nu \mathrm{P}} x[\langle e, t\rangle \lambda y\right.$ John file $y]\left[{ }_{\langle e, t\rangle} \lambda z\right.$ without PRO reading $\left.\left.z\right]\right]$ ? $\approx$ Which articles $x$ are such that John filed $x$ without PRO reading $x$ ?

A crucial assumption for Nissenbaum's account is that movement which licenses parasitic gaps involves abstraction over individual (type $e$ ) variables. Taking this idea at face value, juxtaposing Nissenbaum's theory with the theory of chain interpretation laid out in the previous section leads to an interesting prediction: parasitic gaps should be licensed below the copy privileged for restrictor interpretation, but not above it. Traces below the privileged copy will be bound using abstraction over individuals, with this process of abstraction creating new positions to which a pg-containing adjunct can adjoin. Traces above this copy will be interpreted

${ }^{4}$ To simplify the presentation, we represent the agent as reconstructed into its base position here; see related discussion in Nissenbaum 2000b. 
via choice function binding, which will not create positions to which a pg-containing adjunct can adjoin.

Evidence from long-distance wh-movement suggests that the analysis is on the right track. Consider first the following sentences, involving both long-distance $w h$-movement of a phrase containing an anaphor and the presence of a pg-containing adjunct in the lower clause. Here we see that the anaphor may be bound by both the subject of the embedded clause and the subject of the matrix clause.

(16) Low pg-containing adjunct (modifying treasure):

a. $\checkmark$ [Which picture of herself $\left.f_{\mathrm{A}}\right]$ did Amy say

b. $\checkmark$ [Which picture of himself $\left.{ }_{\mathrm{B}}\right]$ did Amy say

[that Bob will treasure _ after receiving $\underline{p g}$ ].

[that Bob will treasure _ after receiving $\underline{p g}$ ].

Consider now what happens when the pg-containing adjunct is adjoined to the matrix clause. In (17), the choice of adjunct is meant to bias towards a parse where the pg-containing adjunct is part of the matrix clause. In (18), placing the adjunct between the matrix verb and the embedded clause precludes an interpretation where the adjunct is part of the embedded clause. In both of these cases where the wh-phrase licenses a parasitic gap in a matrix clause adjunct, we see that the anaphor contained in the wh-phrase may be bound only by the matrix subject.

(17) High pg-containing adjunct (modifying say):

a. $\checkmark$ [Which picture of herself $f_{\mathrm{A}}$ ] did Amy say [that Bob would love

b. *[Which picture of himself $\mathrm{B}]$ did Amy say [that Bob would love

before buying $\underline{p g}$.

before buying $\underline{p g}$

(18) High pg-containing adjunct (modifying say) in parenthetical position:

a. $\checkmark$ [Which picture of herself $\mathrm{A}]$ did Amy say, before buying $\underline{p g}$, that Bob would love

b. *[Which picture of himself $\mathrm{B}]$ did Amy say, before buying $\underline{p g}$,

that Bob would love

In the grammatical cases, the pg-containing adjunct adjoins below the interpreted NP, along the "path" of a chain interpreted through abstraction of individual variables — in particular, it may adjoin to any of the derived predicate positions created through said abstraction. In the bad cases, namely $(17 \mathrm{~b}, 18 \mathrm{~b})$, binding of the anaphor by the lower subject will require the NP containing that anaphor to be interpreted in the lower clause. Higher links must then be interpreted through choice function binding, which fails to create the right sort of position for a $p g$-containing adjunct to adjoin to.

(19) Parasitic gaps are licensed below the NP:

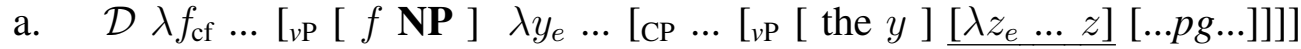

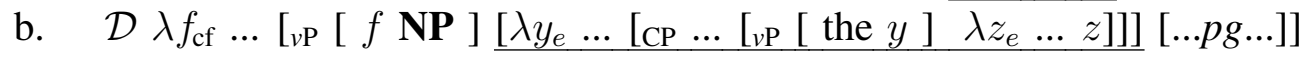

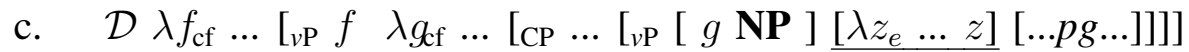

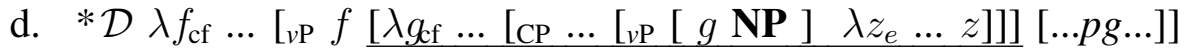


4.2. WeAK CROSSOVER. Similar effects are observed in weak crossover configurations. Weak crossover, or WCO, refers to the inability of a pronoun to be bound by a phrase which has $\bar{A}$-moved across it, where the pronoun itself does not bind the Â-gap (Postal, 1971; Wasow, 1972; see Safir, 2017). (20), illustrating this configuration, shows that a wh-moved object cannot bind a pronominal possessor contained within a subject that it moves over.

(20) ? Who does [his ${ }_{i}$ mother] like _ _i ?

(Ruys, 2000: 513)

WCO effects are notoriously "weak" (Wasow, 1972) and variable, depending on the type of movement (see e.g. Lasnik and Saito, 1991; also below) and pronoun's position. Of particular interest to us is the weakening of WCO effects in long-distance movement configurations. In (21a), we see that the bound pronominal is contained in the subject of the embedded clause. There the WCO effect - if present at all — is markedly weaker than the effect in (21b), where the bound pronominal is contained in the subject of the matrix clause.

\section{WCO even weaker with lower pronouns in long-distance movement:}

(Mahajan 1991: 92 reproduced in Ishii 2006: 158, with judgment marks from Ishii)

a. $\checkmark[\text { Which man }]_{\mathrm{i}}$ does John believe [that [his $\mathrm{s}_{\mathrm{i}}$ mother] hates i]?

b. *? [Which man $]_{\mathrm{i}}$ does [his $\mathrm{s}_{\mathrm{i}}$ mother] believe [that John hates __i]?

As proposed before, there are in principle two modes of chain interpretation available for $\bar{A}$-chains. One involves abstraction over individuals, the other does not. In work pursuing a theory of chain interpretation which does not abstract over individuals, Sauerland (1998) and Ruys (2000) propose that WCO is a property of movement that does not involve abstraction over individuals, a proposal which we adopt. The contrast in (21) above, on this approach, would suggest that abstraction over individuals is an option for intermediate movement through $\mathrm{Spec}, \mathrm{CP}$, but is markedly less available for terminal movement to $\mathrm{Spec}, \mathrm{CP}$.
a. $\quad \lambda f_{\mathrm{cf}} \ldots\left[\ldots \operatorname{pro}_{\mathrm{i}} \ldots\right] \ldots f(\ldots) \ldots$
$\Rightarrow$ variable binding impossible
b. $\quad \lambda x_{e} \ldots\left[\ldots \operatorname{pro}_{\mathrm{i}} \ldots\right] \ldots x \ldots$
$\Rightarrow$ variable binding possible if $\llbracket p r o \rrbracket=x$ (co-indexed with trace)

This approach to WCO leads us to a specific prediction: Ā-movement should exhibit WCO above the privileged copy for NP interpretation, but should feed pronominal binding below this position. This prediction is indeed borne out, as we see below in (23). In (23a), we see that when an anaphor contained within a phrase undergoing long-distance wh-movement is bound by the subject of the matrix clause, the wh-phrase may itself bind a variable contained in the subject of the embedded clause. In contrast, in (23b), we see that when the anaphor is itself bound by the subject of the embedded clause, the wh-phrase which contains it cannot bind a variable in the subject of the embedded clause. ${ }^{5}$

\footnotetext{
${ }^{5}$ We might, of course, worry that (23) is out as a result of a version of the Bach-Peters effect, rather than the result of WCO. The following examples remove this potential confound, showing that WCO is indeed at play in the configurations under consideration.
}

(i) a. $\checkmark$ [Which painting of himself $]_{\mathrm{j}}$ did George $_{\mathrm{j}}$ say [that [its $\mathrm{c}_{\mathrm{i}}$ current owner] told Laura to buy __ i]?

b. ?? [Which painting of herself $\left.{ }_{\mathrm{k}}\right]_{\mathrm{i}}$ did George say [that [its $\mathrm{i}_{\mathrm{i}}$ current owner] told Laura $\mathrm{k}_{\mathrm{k}}$ to buy __ $\mathrm{i}$ ]? 
(23) a. ${ }^{\checkmark}$ [Which painting of himself $\left.]_{\mathrm{j}}\right]_{\mathrm{i}} \operatorname{did}$ George $_{\mathrm{j}}$ say [that [its $\mathrm{i}_{\mathrm{i}}$ owner] hates __ $\mathrm{i}_{\mathrm{i}}$ ]?

b. ?? [Which painting of herself $\left.{ }_{\mathrm{k}}\right]_{\mathrm{i}}$ did George say [that [its $\mathrm{s}_{\mathrm{i}}$ owner $]_{\mathrm{k}}$ hates _ $\left.{ }_{\mathrm{i}}\right]$ ?

If the anaphor is to be bound by the matrix subject, as in (24a), the privileged position for the NP must be sufficiently local to the matrix subject for a binding relationship to be established. This minimally is in Spec,CP of the embedded clause, as the following contrast in (24) illustrates.

(24) a. *George wondered [CP if Mary bought [the picture of himself]].

b. ${ }^{\checkmark}$ George wondered [CP [which picture of himself] Mary likes].

Crucially, the position occupied by the wh-phrase is above the subject of the embedded clause: chains below this position must therefore be interpreted using abstraction over individuals, which feeds binding of individual variables and thus allows the fronted phrase to bind the pronominal possessor of the embedded clause. In contrast, in (23b), the reflexive forces the NP to be interpreted in the embedded clause, below the subject. Chains above this position must be interpreted through choice function binding, which cannot feed variable binding, thus producing a WCO effect.

4.3. SummarY. We have proposed that the NP restrictor of an element undergoing $\bar{A}$-movement may be interpreted in exactly one copy in the movement chain, and that its interpretation above and below the copy with the interpreted NP involves different semantic mechanisms of chain interpretation. We have seen that this proposal makes specific predictions about the properties of long-distance movement chains in which Condition A forces the NP restrictor to be interpreted (reconstructed) in one particular lower copy: above this position, we expect the presence of WCO effects and for the licensing of parasitic gaps to be impossible; below this position, we expect the absence of WCO effects and for the licensing of parasitic gaps to be possible. The diagram in (25) summarizes the two different modes of interpretation which may be involved in the interpretation of a single $\bar{A}$-chain at LF and their distinct properties.

$$
\begin{aligned}
& \text { Two sets of behaviors in an } \bar{A} \text {-chain, above and below the NP at LF: }
\end{aligned}
$$

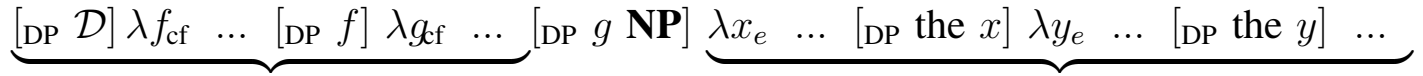

$$
\begin{aligned}
& \text { Above the NP: } \\
& \text { Choice function abstraction } \\
& \text { WCO (Sauerland, 1998; Ruys, 2000) } \\
& \text { No parasitic gaps }
\end{aligned}
$$

5. Types of $\overline{\mathbf{A}}$-movement. We have thus far discussed only English $w h$-movement as our test case for $\bar{A}$-movement behavior. We've seen that the position that the moved DP's restrictor is interpreted in splits a single $\overline{\mathrm{A}}$-chain into two parts, with distinct behaviors. Interestingly, Postal $(1994,1998)$ has observed that different types of $\bar{A}$-movement can be classified into those which are susceptible to WCO and those which license parasitic gaps: ${ }^{6}$

\footnotetext{
${ }^{6}$ Somewhat confusingly, Postal terms these two classes of $\bar{A}$-movement "A-extraction" and "B-extraction"; the former, in particular should not be confused with the more familiar "A-movement."
} 
(26) Postal's (1994) two types of $\overline{\mathbf{A}}$-movement:

a. Susceptible to WCO ("A-extraction”):

$\overline{w h}$, restrictive relatives, neg-inversion, free relatives, comparative extraction...

b. Licenses parasitic gaps ("B-extraction”):

$\overline{w h}$, restrictive relatives, topicalization, non-restrictive relatives, clefting...

Note that wh-movement appears on both lists - a point we return to below.

Postal observes that this A-vs B-extraction split among A--movement types in (26) tracks a number of other contrasting behaviors:

(27) Behaviors of Postal's A- vs B-extractions:

$\begin{array}{lccc}\text { Diagnostic } & \text { "A-extraction" } & \text { "B-extraction" } & \\ \text { Licenses parasitic gaps } & \times & \bigcirc & \\ \text { Shifts nuclear stress } & \times & \bigcirc & \\ \text { Susceptible to WCO } & \bigcirc & \times \\ \text { Ok from anti-pronominal position } & \bigcirc & \times \\ \text { Weak island sensitive } & \bigcirc & \text { limited }\end{array}$

For example, consider the interaction of the two extraction types with so-called anti-pronominal positions. Anti-pronominal positions are those which reject (weak) pronouns. An example of an anti-pronominal position is the result color argument of a change of color verb such as paint in (28) below; see Postal 1994 for a more exhaustive list. As we see through the contrast in $(28 \mathrm{~b}-\mathrm{c})$, A-extraction type $\overline{\mathrm{A}}$-movement may take place from these positions, but Bextraction type $\overline{\mathrm{A}}$-movement may not.

(28) Antipronominal position: change of color contexts

(Postal, 1994: 169, 163-164)

a. * They painted their porch green $_{\mathrm{i}}$ but I refused to paint mine $i t_{\mathrm{i}}$.

b. No such color would I ever paint my car __. $\quad$ (neg-inversion = A-extraction)

c. * That color, he never painted the car _. $\quad$ (topicalization = B-extraction)

As noted above, English wh-movement may at least in principle be either extraction type. But it may have only one set of these properties at a time, as shown below. In (29), we see that movement from an anti-pronominal position - restricted to cases of A-extraction - causes wh-movement to fail to license parasitic gaps. In (30), we see that movement out of a weak island - restricted to cases of B-extraction - causes extraction from an anti-pronominal position to fail.

(29) From antipronominal position $\Rightarrow \mathbf{A}$, parasitic gap $\Rightarrow \mathbf{B}$ :

Which color did you paint your house $(*[$ despite not really liking $p g])$ ?

(30) From antipronominal position $\Rightarrow \mathbf{A}$, extraction from weak island $\Rightarrow \mathrm{B}$ :

*Which color did you wonder [whether John painted his house __ ]?

In his account of the distinction between extraction types, Postal (1994: 162) proposed that "B-extractions obligatorily involve (invisible) resumptive pronouns in their extraction sites, whereas A-extractions do not." In other words, trace positions of B-extractions are a type of unpronounced weak pronoun, explaining their inability to originate in an anti-pronominal position. See Branan and New to appear for more on (unpronounced) weak pronouns and anti- 
pronominal positions. See also similar intuitions in Cinque 1990 (discussed by Postal) and Lasnik and Stowell 1991.

On the theory proposed here, Postal's A- vs B-extraction split tracks the positions where the moved DP's NP restrictor is interpreted at LF. A-extractions must interpret the NP in their base position. B-extractions, in contrast, cannot interpret the NP in their base position. Ambiguous cases of extraction simply display no particular restriction on the position that the chain's NP is interpreted in.

(31) a. "A-extractions" interpret the NP in the base/gap position.

b. "B-extractions" do not interpret the NP in the base/gap position.

c. A/B-ambiguous extractions (like English wh-movement and restrictive relatives) allow for the NP to be interpreted in different positions.

Note that some of the properties listed in (27) are those predicted by our theory. Movement above the NP - i.e. Postal's A-extraction - is interpreted without the use of binding of individual variables, and thus cannot license parasitic gaps and produces what we call a WCO effect. Movement below the NP - Postal's B-extraction - is interpreted through the use of binding of individual variables, and thus licenses parasitic gaps and does not yield WCO effects. Furthermore, this explains why B-extraction is blocked from anti-pronominal positions. Below the NP, traces are interpreted as bound minimal definite descriptions (e.g. [ the $x$ ]), which are formally identical to pronouns (see e.g. Elbourne, 2005), thus explaining Postal's intuition that traces of B-extractions are a type of pronoun. ${ }^{7}$ We leave a total theory of all the properties enumerated a topic for future work.

6. Conclusion. This paper presented a new conception of DP $\bar{A}$-chain interpretation at LF, motivated in part by Barss' observations on Condition A reconstruction. The core idea is that the NP restrictor in these chains is interpreted exactly once, in exactly one position. Links in the chain above and below this position behave differently, corresponding to Postal's independently observed classification of $\bar{A}$-extraction types:

(32) A mnemonic for Postal's extraction types:

a. Above the NP $=$ Postal's "A" extractions

b. Below the NP = Postal's "B" extractions

We proposed that these behaviors are explained by two different modes of chain conversion above and below the NP. Below the NP, chains are interpreted through a process of Trace Conversion and abstraction over individuals. Above the NP, chains are interpreted through some other process - here described as choice function binding - which crucially does not involve abstraction over individuals.

Much work remains. Considerations of Condition A reconstruction for other $\bar{A}$-movement types, and reconciliation of the proposal made here with existing work on Condition $\mathrm{C}$ reconstruction (e.g. Lebeaux, 1991; Heycock, 1995; Romero, 1998; Fox, 1999) and related work on A-movement (e.g. Takahashi and Hulsey, 2009) are pressing matters.

\footnotetext{
${ }^{7}$ For two recent approaches to antipronominal positions, see Stanton 2016 and Poole 2017. Note that, if we interpret the portion of the chain above the NP using choice functions which do not force quantificational reconstruction, we do not derive Poole's generalization that movement from antipronominal positions obligatorily quantificationally reconstructs, suggesting that choice function binding may not be the correct alternative binding mechanism.
} 


\section{References}

Abels, Klaus \& Luisa Martí. 2010. A unified approach to split scope. Natural Language Semantics 18. 435-470. https://doi.org/10.1007/s11050-010-9060-8.

Adger, David, Alex Drummond, David Hall, and Coppe van Urk. 2017. Is there condition C reconstruction? Proceedings of NELS 47.

Barss, Andrew. 1986. Chains and anaphoric dependence. Cambridge, MA: MIT dissertation.

Barwise, Jon, and Robin Cooper. 1981. Generalized quantifiers and natural language. Linguistics and Philosophy 4. 159-219. https://doi.org/10.1007/BF00350139.

Belletti, Adriana, and Luigi Rizzi. 1988. Psych-verbs and $\theta$-theory. Nat Lang Linguist Theory 6. 291-352 https://doi.org/10.1007/BF00133902.

Bhatt, Rajesh. 2002. The raising analysis of relative clauses: Evidence from adjectival modification. Natural Language Semantics 10. 43-90. https://doi.org/10.1023/A:1015536226396 .

Bobaljik, Jonathan David. 1995. Morphosyntax: The syntax of verbal inflection. Cambridge, MA: MIT dissertation.

Bobaljik, Jonathan David. 2002. A-chains at the PF-interface: Copies and 'covert' movement. Nat Lang Linguist Theory 20. 197-267. https://doi.org/10.1023/A:1015059006439.

Branan, Kenyon \& Keely New. To appear. Pronominal paradigms in two varieties of English. Proceedings of WCCFL 38.

Bruening, Benjamin \& Al Khalaf. 2019. No argument-adjunct asymmetry in recon- struction for Binding Condition C. Journal of Linguistics 55. 247-276.

Chomsky, Noam. 1993. A minimalist program for linguistic theory. In Kenneth Hale \& Samuel Jay Keyser (eds.), The view from Building 20, 1-52. Cambridge, MA: MIT Press.

Cinque, Guglielmo. 1990. Types of $A$ '-dependencies. Cambridge, MA: MIT Press.

Elbourne, Paul. 2005. Situations and individuals. Cambridge, MA: MIT Press.

Engdahl, Elisabet. 1983. Parasitic gaps. Linguistics and Philosophy 6. 5-34.

Epstein, Samuel David, Erich M. Groat, Ruriko Kawashima, and Hisatsugu Kitahara. 1998. A derivational approach to syntactic relations. Oxford: Oxford University Press.

Erlewine, Michael Yoshitaka. 2014. Movement out of focus. Cambridge, MA: MIT dissertation..

Fox, Danny. 1999. Reconstruction, binding theory, and the interpretation of chains. Linguistic Inquiry 30. 157-196. https://www.jstor.org/stable/4179058.

Fox, Danny. 2002. Antecedent-contained deletion and the copy theory of movement. Linguistic Inquiry 33. 63-96. https://doi.org/10.1162/002438902317382189.

Heycock, Caroline. 1995. Asymmetries in reconstruction. Linguistic Inquiry 26. 547-570. https://www.jstor.org/stable/4178914.

Ishii, Toru. 2006. A nonuniform analysis of overt wh-movement. Linguistic Inquiry 37. 155-167. https://doi.org/10.1162/ling.2006.37.1.155.

Karttunen, Lauri. 1977. Syntax and semantics of questions. Linguistics and Philosophy 1. 3-44.

Lasnik, Howard \& Mamoru Saito. 1991. On the subject of infinitives. Proceedings of CLS 27(1). 324-343.

Lasnik, Howard, and Tim Stowell. 1991. Weakest crossover. Linguistic Inquiry 22. 687-720. https://www.jstor.org/stable/4178746.

Lebeaux, David. 1991. Relative clauses, licensing, and the nature of the derivation. In Susan D. Rothstein (ed.), Perspectives on phrase structure: Heads and licensing, 175-194. New York: Academic Press.

Mahajan, Anoop. 1991. Operator movement, agreement, and referentiality. MIT Working Papers in Linguistics. 77-96. 
Nissenbaum, Jon. 2000a. Covert movement and parasitic gaps. Proceedings of NELS 30(2). 541555.

Nissenbaum, Jonathan W. 2000b. Investigations of covert phrase movement. Cambridge, MA: MIT dissertation.

Nunes, Jairo. 2004. Linearization of chains and sideward movement. Cambridge, MA: MIT Press.

Pesetsky, David. 2000. Phrasal movement and its kin. Cambridge, MA: MIT Press.

Poole, Ethan. 2017. Movement and the semantic type of traces. Amherst, MA: University of Massachusetts dissertation.

Postal, Paul M. 1971. Cross-over phenomena. New York: Holt, Rinehart, and Winston.

Postal, Paul M. 1994. Contrasting extraction types. Journal of Linguistics 30. 159-186.

Postal, Paul M. 1998. Three investigations of extraction. Cambridge, MA: MIT Press.

Richards, Norvin. 2018. Nuclear stress and the life cycle of operators. In Laura R. Bailey \& Michelle Sheehan (eds.), Order and structure in syntax: Word order and syntactic structure, 217-240. Berlin: Language Science Press.

Romero, Maribel. 1998. Focus and reconstruction effects in wh-phrases. Amherst, MA: University of Massachusetts dissertation.

Romoli, Jacopo. 2015. A structural account of conservativity. Syntax-Semantics Interface 2. 2857.

Ruys, Eddy G. 2000. Weak crossover as a scope phenomenon. Linguistic Inquiry 31. 513-539. https://www.jstor.org/stable/4179116.

Safir, Ken. 2017. Weak crossover. In Martin Everaert \& Henk van Riemsdijk (eds.), Blackwell companion to syntax, Hoboken, NJ: Wiley-Blackwell.

Sauerland, Uli. 1998. The meaning of chains. Cambridge, MA: MIT dissertation.

Sauerland, Uli. 2004. The interpretation of traces. Natural Language Semantics 12. 63-127. https://doi.org/10.1023/B:NALS.0000011201.91994.4f.

Stanton, Juliet. 2016. Wholesale late merger in $\bar{A}$-movement: Evidence from preposition stranding. Linguistic Inquiry 47. 89-126. https://doi.org/10.1162/LING_a_00205 .

Stockwell, Richard, Aya Meltzer-Asscher \& Dominique Sportiche. To appear. There is reconstruction for Condition C in English questions. Proceedings of NELS 51.

Takahashi, Shoichi \& Sarah Hulsey. 2009. Wholesale Late Merger: Beyond the A/A distinction. Linguistic Inquiry 40: 387-426. https://doi.org/10.1162/ling.2009.40.3.387.

Uriagereka, Juan. 1988. On movement. Storrs, CT: University of Connecticut dissertation.

Wasow, Thomas. 1972. Anaphoric relations in English. Cambridge, MA: MIT dissertation.

Wierzba, Marta, Martin Salzmann \& Doreen Georgi. To appear. An experimental investigation of reconstruction for Condition C in German A'-movement. Proceedings of CLS 56. 